Discussion Paper No. 14-121

On the Effects of Unilateral Environmental Policy on Offshoring in Multi-Stage Production Processes

Oliver Schenker, Simon Koesler, and Andreas Löschel

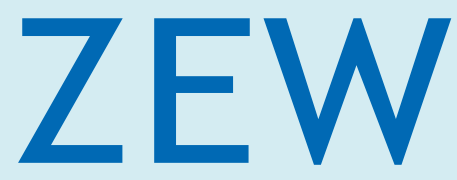

Zentrum für Europäische Wirtschaftsforschung $\mathrm{GmbH}$

Centre for European

Economic Research 
Discussion Paper No. 14-121

\title{
On the Effects of Unilateral Environmental Policy on Offshoring in Multi-Stage Production Processes
}

\author{
Oliver Schenker, Simon Koesler, \\ and Andreas Löschel
}

Download this ZEW Discussion Paper from our ftp server:

http://ftp.zew.de/pub/zew-docs/dp/dp14121.pdf

Die Discussion Papers dienen einer möglichst schnellen Verbreitung von neueren Forschungsarbeiten des ZEW. Die Beiträge liegen in alleiniger Verantwortung der Autoren und stellen nicht notwendigerweise die Meinung des ZEW dar.

Discussion Papers are intended to make results of ZEW research promptly available to other economists in order to encourage discussion and suggestions for revisions. The authors are solely responsible for the contents which do not necessarily represent the opinion of the ZEW. 


\title{
On the Effects of Unilateral Environmental Policy on Offshoring in Multi-Stage Production Processes
}

\author{
Oliver Schenker ${ }^{\dagger *} \quad$ Simon Koesler ${ }^{\dagger} \quad$ Andreas Löschel ${ }^{\dagger \dagger}$
}

December 19, 2014

\begin{abstract}
In the last decades supply chains emerged that stretch across many countries. This has been explained with decreasing trade and communication costs. We extend the literature by analyzing if and how unilateral environmental regulation induces offshoring to unregulated jurisdictions. We first apply an analytical partial-equilibrium model of a two-stage production process that can be distributed between two countries and investigate unilateral emission pricing and its supplementation with border carbon taxes. To get a more comprehensive picture, we subsequently apply a computable general equilibrium model that includes a better representation of international supply chains. We find heterogeneous, but mostly positive effects of a unilateral carbon emission reduction by the European Union on the degree of vertical specialisation of European industries and explain these differences by heterogeneity in the emission-intensity and pre-policy vertical specialisation of sectors. Border taxes are successful in protecting upstream industries, but with negative side effects for downstream industries.
\end{abstract}

Keywords: Unilateral Climate Policy, Border Carbon Taxes, Vertical Specialisation, Offshoring, Outsourcing, Computable General Equilibrium

JEL-Classification: C68, F12, F18, Q58

\footnotetext{
*Corresponding author, Email: schenker@zew.de, Phone: +49 621 1235-229

${ }^{\dagger}$ Centre for European Economic Research (ZEW), L7,1, D-68161 Mannheim, Germany

†Westfälische Wilhelms-Universität Münster, Chair of Economics, esp. Energy and Resource Economics, Am Stadtgraben 9, D-48143 Münster, Germany
} 


\section{Introduction}

Actuated by decreasing trade, transportation and communication costs, supply chains that stretch across many countries have emerged in the last decades. Dietzenbacher, Pei, and Yang (2012) for example report that exports of processed goods, where the major part of intermediates are imported from abroad and then assembled for re-exporting, accounted for more than 50 percent of China's exports in the period 1996-2007. Much has been written about the emergence of off-shoring and vertical specialisation. Grossman and Rossi-Hansberg (2006) argued that this fundamentally changed the nature of international trade and state that "[i] ts not wine for cloth anymore".

According to Hummels, Ishii, and Yi (2001), who used input-output data for the years 1970 to 1990 to compute international trade induced by vertical specialisation, most supply chains in this timespan integrated only industries from industrialized countries. But in a process that Baldwin and Lopez-Gonzalez (forthcoming) termed "globalization's second unbundling", less developed countries have been integrated in these supply chains too. Grossman and Rossi-Hansberg (2008, 2012) and Costinot, Vogel, and Wang (2012) explain the evolution of such supply chains with decreasing costs of managerial efforts to supervise and assure the quality of processed intermediate goods.

Although it is indisputable that the technological advancements that reduced communication and trade costs are the most important driver of the emergence of global supply chains, we argue that differences in regulation between countries provide additional incentives to offshore certain production stages to countries with lower regulation costs. An evident example are differences in environmental regulation. Developed countries have often more stringent environmental regulations compared to developing ones. The well-known pollution haven hypothesis argues that polluting industries escape from environmental regulation in developed countries by moving to unregulated developing countries. This in turn makes unilateral environmental regulation less effective. The most prominent example is the so-called "carbon leakage effect" which proposes that a unilateral regulation of greenhouse gas (GHG) emissions may rise production costs of carbon-intensive goods and reduce the competitiveness of producers in regulated countries, leading to a shift of production to unregulated ones.

But industries may respond to regulation not only with a complete shift of the production but with the offshoring of single production stages along the vertical supply chain 
and thereby contribute to the "second unbundling". In spite of the large literature on how international trade affects the effectiveness of environmental regulation, almost all studies assess the topic through the lens of "horizontal specialisation", i.e. specialisation in final goods, and ignoring the role of intermediate goods. Exceptions are the papers of Benarroch and Weder (2006) and McAusland (2004) which study trade in intermediates and their environmental consequences in industries with increasing returns to scale, but focus rather on the economies of scale than the disentangling of the supply chain effects.

Including the supply chain effects in the analysis has also important implications for policy conclusions. Most analysis of unintended side effects of unilateral carbon emission regulation focus on so called "energy intensive, trade exposed" industries which are characterized by the high energy use of their final production stage, their high export shares, and the high substitutability of their goods on international markets. But this classification ignores the sectors vulnerability to upstream supply chain disruptions and the emissions embodied in the supply chains. Since more than half of international trade volumes are trade in intermediates, this may have important consequences for policy design. ${ }^{1}$ This paper aims to close this gap by analyzing the effects on the supply chain composition of two unilateral environmental policy measures.

We first investigate a sole emission price paid by domestic industries. Examples are the European Union Emissions Trading System (EU ETS) that regulates carbon emissions in most EU energy-intensive industries or the $\mathrm{SO}_{2}$ Reductions and Allowance Trading in the United States. Subsequently, we study the effects of a carbon price in combination with a tax on imported embodied emissions. Although it has so far not been applied in practice, a border tax on carbon has been widely debated - both among academics and policy makers - as a supplement to climate policy measures in order to respond to the losses in competitiveness and effectiveness that accompany such measures if implemented unilaterally. The idea was incorporated for example in the Waxman/Markey bill (H.R. 2454 "The American Clean Energy and Security Act of 2009"), an in the end unsuccessful attempt to regulate U.S. carbon emissions, but has also been discussed in Europe in addition to the EU ETS. ${ }^{2}$

\footnotetext{
${ }^{1}$ Sturgeon and Memedovic (2010) report that in 200656 percent on total world imports were intermediate goods.

${ }^{2}$ See Markusen (1975) and Copeland (1996) for an early analysis. They find that a border tax belongs to the optimal policy portfolio in case of an unilateral regulation of trans-boundary pollutants. More
} 
In order to illustrate the general effects those regulations have on offshoring decisions, we use in a first step a partial equilibrium model of a two stage production process with two regions. The model blends Ricardian international trade in a continuum of goods (Dornbusch, Fischer, and Samuelson 1977) and multi-stage production as in Yi (2003) with a model of a pollutant-emitting production as in Copeland and Taylor (1994). Not surprisingly, we find that emission pricing polices force more emission-intensive producers to shift a greater share of their supply chain to the unregulated region and thereby increasing vertical specialisation. Border taxation of emissions in turn retains these stages at home that would be off-shored due to the unilateral regulation alone. But this comes at the cost of losing market shares in non-regulated regions for goods depending on emissionintensive, and thus more costly, upstream intermediates. This effect could, at least in theory, even cause an increase in carbon leakage rates.

In reality, supply chains are a complex interweaved network of sectoral relationships. So, eventually, we extend the partial equilibrium model and apply a new full fledged computable general equilibrium (CGE) model featuring for the first time an explicit specification of international trade flows between sectors in different regions. This feature is vital for studying changes in global supply chains as it allows to trace intermediate flows through the global economy. The CGE model is calibrated to the multi-regional input-output data of the World Input-Output Database (WIOD) that maps trade flows between sectors and regions. We solve this model numerically to analyse the effect of a 20 percent carbon emission reduction through an ETS in the EU - a stylized representation of the EU's emission reduction targets for 2020 - on the supply chains of European industries. As in the analytical model and counterfactual, we supplement this policy with a border tax on imported carbon emitted in unregulated regions. The simulated results show that a unilateral 20 percent emission reduction in the EU has heterogeneous impacts on the induced offshoring, measured as the change in foreign factor content in domestic output, of industries depending on the emission-intensity of their supply chain. The pattern is however more diverse compared to the analytical model, which can be explained by heterogeneity in pre-policy vertical specialization and substitution elasticities. If the domestic carbon price is complemented with a border carbon tax, vertical specialisation recently, Fischer and Fox (2012) provide a numerical analysis of specific border carbon tax schemes, showing that these schemes can support domestic competitiveness but have almost no effect on global carbon emissions. 
decreases in virtually all sectors, again with the largest impact on emission-intensive sectors. However, almost all European sectors that are subject to the border carbon tax have to cope with a small market share loss in foreign regions.

The remainder of this paper is structured as follows: In the next section, we lay out the analytical model and illustrate the general effects of unilateral regulation on vertical specialisation. Subsequently, we enlarge the model. Before applying the CGE model, the current state of fragmentation in the production of European final goods and their consequence in terms of foreign emission embodied in European goods is briefly examined. Next, we investigate the implications of the two policies on vertical specialisation in the numerical model and contrast our findings with the analytical model. Finally, we conclude and discuss the policy implications of our results.

\section{An Analytical Framework of Offshoring}

In this section, we lay out an analytical model that provides intuition how environmental regulation can affect offshoring decisions of fragments of the supply chain. The model blends Ricardian international trade in the tradition of Dornbusch, Fischer, and Samuelson (1977) and multi-stage production as in Yi (2003) with a model of different emissionintensive industries as in Copeland and Taylor (1994). This provides a tool to examine the effects of environmental policy on the vertical organization of industries. However, the analysis is for now kept as simple as possible and ignores general equilibrium effects on factor prices and on final demand. For analytical tractability, the analyzed supply chains contain only two stages where a single upstream good is used in the downstream industry and emission-intensity varies between supply chains but not within. These limitations will be addressed below with a more inclusive calibrated general equilibrium model. Nevertheless, the simplified analytical framework provides important insights about the mechanics of offshoring under environmental regulation.

\subsection{Firms and Technology}

We consider a world with two regions $r$, called North $(N)$ and South $(S)$. Following Dornbusch, Fischer, and Samuelson (1977), there is a continuum of goods, indexed by $z \in[0,1]$. Each good $z$ is produced with a single production factor in two stages, a 
upstream (stage 1) and a downstream stage (stage 2) and differs in its emission-intensity of production. Emissions eventually have negative effects on welfare and are thus going to be regulated by an exogenous policy maker, but initially they do no adverse effects on output. The upstream good is a required intermediate input in the downstream industry which eventually produces the final good. We assume constant returns to scale on both stages of production and zero profit in all industries. Further, we assume constant factor prices and no factor mobility across countries but between sectors.

\subsubsection{Upstream Firms}

As in Copeland and Taylor (1994) the upstream production of any good $z$ combines factor $l$ and emissions $d$ in a Cobb-Douglas fashion. ${ }^{3}$

$$
y_{r}^{1}\left(d_{r}^{1}, l_{r}^{1} ; z\right)= \begin{cases}\left(A_{r}^{1} l_{r}^{1}\right)^{1-\alpha(z)} d_{r}^{1 \alpha(z)} & \text { if } d_{r}^{1} \leq \lambda l_{r}^{1} \\ 0 & \text { if } d_{r}^{1}>\lambda l_{r}^{1},\end{cases}
$$

where $0 \leq 1-\alpha(z) \leq 1$ is the value share of factor $l$ and $0 \leq \alpha(z) \leq 1$ is the emission intensity, both vary across industries. Thereby we assume that every good $z$ is produced with the same emission intensity $\alpha(z)$ along its supply chain. ${ }^{4} A_{r}^{1}$ can be interpreted as a stage specific, factor augmenting technology used by region $r$ in stage $1 . \lambda>0$ is a technology efficiency parameter that limits the substitution between factor input and emissions because output must be bounded above for a given factor input. Therefore, production sets where $d_{r}^{1}>\lambda l_{r}^{1}$ are not feasible (see Copeland and Taylor (1994)). In order to avoid corner solutions, we focus on cases where $d_{r}^{1} \leq \lambda l_{r}^{1}$. In those cases, the unit costs of a upstream firm in region $r$ can be characterized by

$$
c_{r}^{1}\left(\tau_{r}, w_{r}, A_{r}^{1} ; z\right)=\phi(z) \tau_{r}^{\alpha(z)}\left(\frac{w_{r}}{A_{r}^{1}}\right)^{1-\alpha(z)},
$$

\footnotetext{
${ }^{3}$ Although a joint product of output in most production processes, we follow Copeland and Taylor (1994) and model emissions as input. This requires that the joint production technologies satisfy certain regularity conditions. See the Appendix of Copeland and Taylor (1994) for a detailed derivation.

${ }^{4}$ Assuming that all production stages feature the same emission intensity is a strong assumption but limits the dimensionality of production and allows for an easier understanding of the supply chain effects. However, the assumption is relaxed later in the paper when we extend the analysis to a more comprehensive general equilibrium context.
} 
where $\phi(z)=(1-\alpha(z))^{\alpha(z)-1} \alpha(z)^{-\alpha(z)}$ is an industry specific constant, $\tau_{r}$ describes the input costs of a unit emissions and $w_{r}$ is the price of the factor. Note that in order to avoid corner solutions $\tau_{r}$ has to be strictly positive.

\subsubsection{Downstream Firms}

The upstream output $y_{r}^{1}(z)$ is a required intermediate input in the downstream production of good z. Upstream products from $N$ and $S$ are perfect substitutes and trade costs are zero, thus the intermediate input will always be sourced from only one region. Following Yi (2003), emissions, the factor input, and the upstream intermediate input are compounded in a nested Cobb-Douglas production function.

$$
y_{r}^{2}\left(x_{r, s}^{2}, d_{r}^{2}, l_{r}^{2} ; z\right)= \begin{cases}{\left[\left(A_{r}^{2} l_{r}^{2}\right)^{1-\alpha(z)} d_{r}^{2 \alpha(z)}\right]^{1-\theta} x_{r, s}^{2 \theta}} & \text { if } d_{r}^{2} \leq \lambda l_{r}^{2} \\ 0 & \text { if } d_{r}^{2}>\lambda l_{r}^{2},\end{cases}
$$

where $x_{r, s}^{2}$ is region $r$ 's use of the upstream good from region $s$ and, similar to stage 1 , $A_{r}^{2}$ is a stage- and region-specific technology that determines factor productivity of stage 2 in region $r . \theta$ is the value share of upstream goods in the downstream industry, which we assume to be constant across industries. Similar to the upstream stage, production sets with $d_{r}^{2}>\lambda l_{r}^{2}$ are not feasible. Downstream output of industry $z$ in region $r$ has unit costs of

$$
c_{r}^{2}\left(\tau_{r}, w_{r}, p_{s}^{1} ; z\right)=\psi(z)\left[\tau_{r}^{\alpha(z)}\left(\frac{w_{r}}{A_{r}^{2}}\right)^{1-\alpha(z)}\right]^{1-\theta}\left(\arg \min \left[p_{\mathrm{N}}^{1}(z), p_{\mathrm{S}}^{1}(z)\right]\right)^{\theta},
$$

where $\psi(z)=(1-\theta)^{\theta-1} \theta^{-\theta} \phi(z)^{1-\theta}$ is a downstream industry specific constant and $p_{s}^{1}(z)$ is the input cost of the upstream intermediate from region $s$ faced by the downstream producer that minimizes her costs.

In order to allow for a clear cut analysis, we structure our economy further and focus on the set of goods that are originally produced entirely in the North. For this a minimal set of additional assumptions are required. In the following, we assume that $1 \leq\left(\frac{w_{N}}{w_{S}}\right) \leq$ $\left(\frac{A_{N}^{1}}{A_{S}^{1}}\right) \leq\left(\frac{A_{N}^{2}}{A_{S}^{2}}\right)$, meaning that $N$ 's relative wage is lower than its productivity of factor $l$ used in both production stages. This eventually implies that in the absence of any unilateral environmental policy (i.e. $\tau_{N}$ equals $\tau_{S}$ ) up- and downstream production take both place in the North. The third inequality $\left(\frac{A_{N}^{1}}{A_{S}^{1}}\right) \leq\left(\frac{A_{N}^{2}}{A_{S}^{2}}\right)$ implies that the North has a relative comparative advantage in the downstream stage. Since Ricardian comparative 
advantage forces determine the composition of the supply chain in equilibrium, a unilateral increase in production costs in $N$ - e.g. induced by an increase in emission costs - affects at the margin first the location of upstream production before downstream production is considered to be offshored. This situation defines the baseline for our analysis.

\subsection{Offshoring due to Unilateral Environmental Regulation}

We turn our attention to two types of policies that have been widely discussed in the literature on environmental regulation in open economies. First, a unilateral increase in the costs of emissions in the North - either caused through an emission tax or through a tightened cap in an ETS that reduces the supply of emission permits and thus increases emission costs - is examined. Subsequently, we analyse the implications of complementing the unilateral emission pricing with a border tax of the North on imported embodied emissions from the South. Both instruments are challenged with the questions (i) how the respective instrument affects the vertical organizational structure of emission-emitting industries and (ii) how the adjustment of supply chains affects the effectiveness of the regulation. Note that although we acknowledge that offshoring decisions and the unbundling of supply chains are mostly driven by many factors such as reductions in communication and trade costs, we remain here agnostic about those driver and focus on environmental regulation as the only offshoring-inducing determinant. ${ }^{5}$

\subsubsection{Unilateral Emission Pricing}

Our starting point is our baseline scenario, where we assume that $\tau_{N}$ equals $\tau_{S}$ and is positive. Now suppose that a policy in $N$ unilaterally increases the costs of emissions, either by an increasing emission tax or by a reduced supply of emission permits under a constant demand of such permits, and therefore $\tau_{N}>\tau_{S}$.

A purchasing manager in the downstream (stage 2) industry has to decide where to source its intermediate input. She buys the intermediate upstream good used in sector $z$ from region $S$ if $c_{S}^{1}\left(\tau_{S}, w_{S} ; z\right) \leq c_{N}^{1}\left(\tau_{N}, w_{N} ; z\right)$. The input costs of the upstream good in the downstream industry is thus $p^{1}(z)=\arg \min \left[c_{S}^{1}\left(\tau_{S}, w_{S} ; z\right), c_{N}^{1}\left(\tau_{N}, w_{N} ; z\right)\right]$. This makes the downstream production in the South conditioned on:

\footnotetext{
${ }^{5}$ See for example Baldwin and Lopez-Gonzalez (forthcoming) for an excellent overview about the the role of trade and communication costs.
} 


$$
A^{1} \equiv \frac{A_{N}^{1}}{A_{S}^{1}} \leq \frac{w_{N}}{w_{S}}\left(\frac{\tau_{N}}{\tau_{S}}\right)^{\frac{\alpha(z)}{1-\alpha(z)}} \equiv \omega T(z) .
$$

Conversely, the upstream good will be sourced from $N$ if $A^{1} \geq \omega T(z)$. With $\tau_{N}>\tau_{S}$ and $\alpha(z)>0, T(z)$ is increasing in $z$. Because of North's relatively higher emission prices, its relative cost advantage in producing the upstream part of good $z$ declines as expenditures for emissions make up a larger share of total costs.

The cut-off emission intensity $\alpha(z)$ of the upstream sector $\underline{z}$ where the purchasing manager is indifferent between offshoring its upstream production to $S$ or keeping it in $N$ can be be found by equalizing inequality (5) and solving for $\alpha(z)$. This leads to:

$$
\alpha(\underline{z})=\frac{\ln \left(\frac{A^{1}}{\omega}\right)}{\ln \left(\frac{\tau_{N}}{\tau_{S}}\right)+\ln \left(\frac{A^{1}}{\omega}\right)}=\underline{\alpha} .
$$

Note that the greater the difference between $\tau_{N}$ and $\tau_{S}$, the lower is the cut-off emission intensity. The same calculus is then used by the final consumers in both regions. Goods of different origin are perfect substitutes and there are no trade costs. Thus, they source the final good $z$ from $S$ if $c_{S}^{2}\left(\tau_{S}, w_{S}, p^{1} ; z\right) \leq c_{N}^{2}\left(\tau_{N}, w_{N}, p^{1} ; z\right)$. We can rewrite this purchase decision as:

$$
A^{2} \equiv \frac{A_{N}^{2}}{A_{S}^{2}} \leq \frac{w_{N}}{w_{S}}\left(\frac{\tau_{N}}{\tau_{S}}\right)^{\frac{\alpha(z)}{1-\alpha(z)}} \equiv \omega T(z) .
$$

The final good is purchased from the North if $A^{2} \geq \omega T(z)$. From $A^{1}<A^{2}$ and Ricardian comparative advantage forces it follows that in equilibrium the final good is never produced in the South if the upstream good is sourced in the North. Equalizing (7) and solving the cut-off emission intensity $\alpha(z)$ of industry $\bar{z}$, for which the final consumer is indifferent between purchasing the final good $z$ from $S$ or $N$, shows that:

$$
\alpha(\bar{z})=\frac{\ln \left(\frac{A^{2}}{\omega}\right)}{\ln \left(\frac{\tau_{N}}{\tau_{S}}\right)+\ln \left(\frac{A^{2}}{\omega}\right)}=\bar{\alpha} .
$$

Thus, every industry with an emission intensity equal or higher than $\bar{\alpha}$ shifts their entire production to $S$. Combining (5) and (7) allows to study the industry structure for given emission prices. Three different production patterns are possible: A good $z$ can either (i) be produced entirely in $N$, it can (ii) be produced entirely in $S$, or (iii) it can consist of a Southern upstream good that is processed to a final good in $N$. The latter describes policy-induced vertical specialisation. 


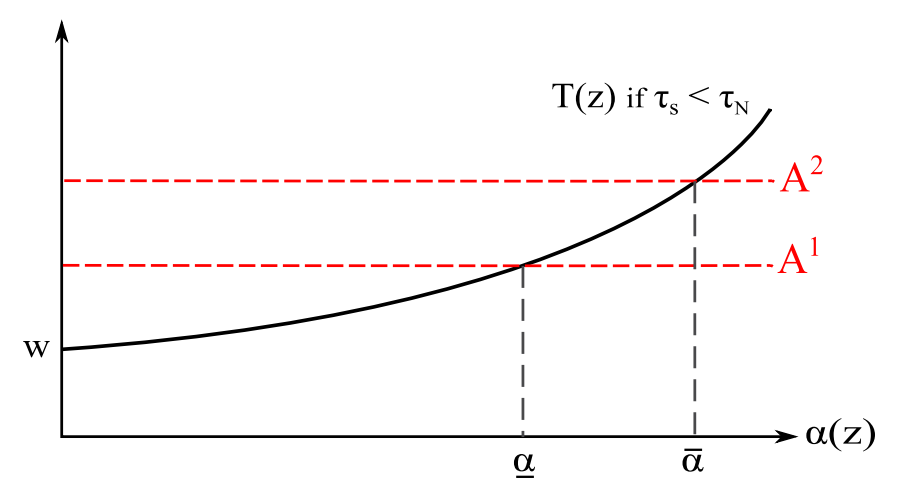

Figure 1: Vertical specialisation at the extensive margin.

Vertical specialisation at the extensive margin. If policy induces a discrete shift in the structure of the supply chain, such that upstream and downstream production is located in different regions, we define this as vertical specialisation at the extensive margin. Industry $z$ produces vertically specialized and offshores its upstream production from the North to the South if:

$$
A^{1} \leq \omega T(z) \leq A^{2}
$$

The offshoring decisions at the extensive margin of the different emission-intensive industries are illustrated in Figure 1. Following Copeland and Taylor (1994), we rank goods according to their emission-intensity which is a strictly increasing function of $\alpha$. The supply chains of industries with emission-intensities of $\alpha(z) \leq \underline{\alpha}(z)$ are not affected by an increase of $N$ 's emission prices. The production of both stages still takes place in $N$. When emission costs account only for a small share of overall costs, comparative advantages based on relative production technologies determine the supply chain. But $\omega T(z)$ has an upward slope. With increasing emission intensity and thus increasing share of emission costs, the $\omega T(z)$ locus cuts $A^{1}$ at $\underline{\alpha}$ from below. We know from condition (5) that if $A^{1}<\omega T(z)$ the upstream production stage is off-shored to $S$. But below the $A^{2}$-line, the final good processing remains in $N$. With increasing emission-intensity, $\omega T(z)$ cuts the $A^{2}$-line and the technological comparative advantage of $N$ 's downstream production stage is dominated by the disadvantage in emission costs for $\alpha(z) \geq \bar{\alpha}$. Thus, the final good processing shifts to $S$ as well.

Insight 1. A unilateral relative increase in emission costs fragments the supply chain and induces offshoring at the extensive margin for medium emission-intensive industries 
between $\underline{\alpha}$ and $\bar{\alpha}$.

The offshoring of the upstream stage of emission-intensive industries to less regulated regions reduces the effectiveness of the unilateral policy and results in so-called carbon leakage. We will asses the magnitude of this effect by using a calibrated CGE model in the next section.

Vertical specialisation at the intensive margin. Since we are interested in the strength of offshoring effects, we focus now on industries with emission-intensities between $\underline{\alpha}<\alpha<\bar{\alpha}$ where environmental regulation results in fragmented supply chains. We define the change in upstream foreign factor content in the domestic downstream output as vertical specialisation at the intensive margin. The change in unit demand for foreign production factor in the upstream industry induced by a marginal change in the domestic emissions costs can be expressed through the cross-price elasticity.

Applying Shepard's Lemma to equation (4) leads to Hicksian demand for the foreign production factor:

$$
\begin{aligned}
x_{r, s}^{2}\left(\tau_{r}, w_{r}, p_{s} ; z\right) & =\frac{\partial c_{r}^{2}\left(\tau_{r}, w_{r}, p_{s} ; z\right)}{\partial p_{s}} \\
& =\psi(z)\left[\tau_{r}^{\alpha(z)}\left(\frac{w_{r}}{A_{r}^{2}}\right)^{1-\alpha(z)}\right]^{1-\theta} \theta\left(\arg \min \left[p_{\mathrm{N}}^{1}(z), p_{\mathrm{S}}^{1}(z)\right]\right)^{\theta-1} .
\end{aligned}
$$

The cross-price elasticity of unit demand for foreign production factor with respect to a change in the domestic emissions prices for industry $z$ is then:

$$
\chi(z)=\frac{\partial x_{r, s}^{2}\left(\tau_{r}, w_{r}, p_{s} ; z\right)}{\partial \tau_{r}} \frac{\tau_{r}}{x_{r, s}^{2}\left(\tau_{r}, w_{r}, p_{s} ; z\right)}=\alpha(z)-\alpha(z) \theta \forall \underline{\alpha}<\alpha(z)<\bar{\alpha} .
$$

As $0 \leq \theta \leq 1$ and $0 \leq \alpha(z) \leq 1$, this cross-price elasticity is always positive.

Insight 2. A unilateral marginal increase in North's emission costs increases the intensity of used foreign production factors from the the unregulated South and therewith vertical specialisation at the intensive margin. The increase in foreign factor intensity is increasing with the emission-intensity of industries.

The change in upstream factor intensity from non-regulated regions in the downstream output of regulated industries will be our measure of regulation-induced offshoring, also 
when using the CGE model below. Changes in vertical specialisation at the intensive margin also affect the origin of emissions. While the literature on carbon leakage mainly has focused on changes in the location of production of final goods, leakage can also arise through supply chain adjustments of regulated industries. As fragmented industries increase the content of parts offshored to unregulated regions the overall production of a good might become more emission-intensive. We investigate the magnitude of this "within-supply chain" carbon leakage using the CGE model later in this paper.

\subsubsection{Unilateral Emission Pricing with Border Emission Taxes}

Suppose that the policy makers in the North want to tackle the adverse effects on competitiveness and policy efficiency that $N$ 's unilateral environmental policy causes and add a border tax on embodied emissions imported from $S$ to the domestic emission regulation set. The border tax aims at leveling the playing field on the domestic market and taxes each unit of imported carbon emissions that has been used in the production of the good with the difference in its respective emission price $\left(\tau_{N}-\tau_{S}\right){ }^{6}$

Border emission taxes on intermediate good markets. A unit of a upstream good from industry $z$ produced in $S$ contains embodied emissions:

$$
\begin{aligned}
E_{S}^{1}(z) & =\frac{d_{S}^{1}}{y_{S}^{1}} \\
& =\left(\frac{\alpha(z)}{1-\alpha(z)} \frac{w_{S}}{\tau_{S} A_{S}^{1}}\right)^{1-\alpha(z)} .
\end{aligned}
$$

The border emission tax applied on $N$ 's import in industry $z$ of $S$ 's upstream good is thus $t_{N}^{1}(z)=\left(\tau_{N}-\tau_{S}\right) \times E_{S}^{1}(z)$. This term is positive and increases the sourcing costs of intermediates in the $N$ 's downstream industry. A border carbon tax affects the offshoring decision of $N$ 's final good industries and puts a wedge between the prices $N$ and $S$ downstream purchasing managers face. The intermediate sourcing decision of final good producers in $S$ are not affected and are still described by condition (5). This, however, is different for a downstream purchasing manager in $N$.

\footnotetext{
${ }^{6}$ Import taxes are often discussed in combination with export rebates (see e.g. Fischer and Fox (2012)). We focus on import taxes, although the inclusion of export rebates may lead to different findings, in particular in the analysis of final good markets. But where as the compatibility of border taxes with international trade law is already heavily contested, this holds even more for export rebates.
} 
She faces additional costs when sourcing the intermediate input from $S$. Intermediate input costs in $N^{\prime}$ 's downstream industry $z$ are now $p_{N}^{1 *}(z)=\arg \min \left[c_{S}^{1}\left(\tau_{S}, w_{S} ; z\right)+\right.$ $\left.t_{N}^{1}(z), c_{N}^{1}\left(\tau_{N}, w_{N} ; z\right)\right]$, where the asterisk indicates the border carbon tax regime and the subscript the importing region. With some algebra we can derive the following condition: Industry $z$, located in $N$, sources its intermediate input from $S$ if:

$$
A^{1} \Gamma(z) \equiv \frac{A_{N}^{1}}{A_{S}^{1}}\left(\frac{\alpha(z) \tau_{N}+(1-\alpha(z)) \tau_{S}}{\tau_{S}}\right)^{\frac{1}{1-\alpha(z)}} \leq \frac{w_{N}}{w_{S}}\left(\frac{\tau_{N}}{\tau_{S}}\right)^{\frac{\alpha(z)}{1-\alpha(z)}} \equiv \omega T(z) .
$$

Since $\tau_{S}<\tau_{N}, S$ produces the same good $z$ at least not less emission-intensive than $N$. Thus, with border taxes the emission costs per unit imported to $N$ are not lower for any good $z$ produced in $S$ relative to $N$. As a consequence, under a border tax regime in $N, A^{1} \Gamma(z)>\omega T(z)$ holds for all $\alpha(z)$ if $\tau_{N}>\tau_{S}$. This implies that baseline Ricardian comparative advantage forces dominate again and offshoring due to environmental regulation is not a profitable motivation any more. ${ }^{7}$. So eventually downstream producers of good $z$ in $N$ never offshore their upstream production to $S$.

Insight 3. Border emission taxes eliminate offshoring of upstream production stages and fragmentation of supply chains that has been induced by unilateral emission pricing policies, both at the extensive and intensive margin.

Border emission taxes on final good markets. Since border taxes drive a wedge between $N$ and $S$ good markets, also final consumers in $N$ and $S$ face different purchase problems. As showed above, the supply chain of industry $z$ is under a border tax regime either completely located in $S$ or $N$. Thus, no parts of goods that are traded on the $S$ markets crossed the border to $N$ and are hence not affected by the border tax. However, on $N$ markets final goods are potentially available that are entirely produced in $S$ and taxed accordingly when reaching $N$ markets.

By exploiting separability the unit cost function of a final good $z$ produced entirely in $S$ is $c_{S}^{2}=\psi(z) \tau_{S}^{\alpha(z)} w_{S}^{1-\alpha}\left(A_{S}^{21-\theta} A_{S}^{1 \theta}\right)^{\alpha(z)-1}$. Shepard's Lemma shows that one unit of the final good $z$ produced completely in $S$ includes

$$
E_{S}^{2}(z)=\left(\frac{\alpha(z)}{1-\alpha(z)} \frac{w_{S}}{\tau_{S} A_{S}^{21-\theta} A_{S}^{1 \theta}}\right)^{1-\alpha}
$$

\footnotetext{
${ }^{7} \mathrm{~A}$ formal proof is given in the Appendix A.1
} 


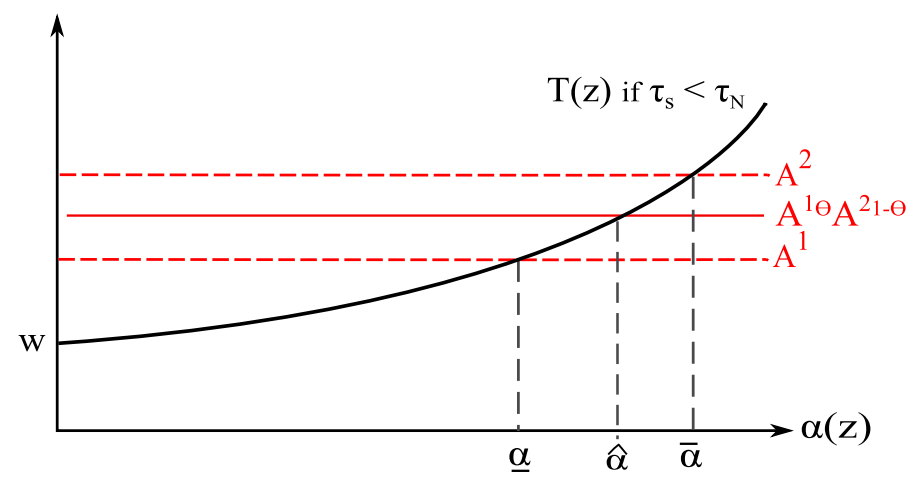

Figure 2: Profitability of industries on the $S$ market in the presence of a border tax

units of emissions and the tax on imported final goods from $S$ is thus $t_{S}^{2}=\left(\tau_{N}-\right.$ $\left.\tau_{S}\right) E_{S}^{2}(z)$. The final consumer in $N$ purchases the final good $z$ from $N$ if $c_{N}^{2}\left(\tau_{N}, w_{N} ; z\right) \leq$ $c_{S}^{2}\left(\tau_{S}, w_{S} ; z\right)+t_{S}^{2}$. Rearranging this condition provides:

$$
\left(A^{1}\right)^{\theta}\left(A^{2}\right)^{1-\theta} \leq \omega T(z) \varphi^{\frac{1}{1-\alpha(z)}} \Gamma(z)
$$

where $\varphi=(1-\theta)^{1-\theta} \theta^{\theta}$. So again pre-policy Ricardian comparative advantages dominate and the North relies only final goods produced entirely domestically.

Insight 4. A border tax on imported embodied emissions implemented by $N$ prevents all effects on $N$ 's final good market induced by $N$ 's unilateral emission pricing.

In the South, the situation looks slightly different. Consumers are not directly confronted with the border tax. But indirectly, since under the border tax regime no goods are available that have been produced in a fragmented manner. Ultimately, a final consumer in $S$ sources the final good from $N$ if $c_{N}^{2}(z) \leq c_{S}^{2}(z)$, that is if:

$$
\left(A^{1}\right)^{\theta}\left(A^{2}\right)^{1-\theta} \leq \omega T(z)
$$

This points out that consumers in $S$ switch from final goods produced in $N$ to goods produced in $S$ emission-intensive industries if the $\omega T(z)$-locus cuts the $\left(A^{1}\right)^{\theta}\left(A^{2}\right)^{1-\theta}$-line from below. Thus, in contrast to a regime with unilateral domestic emission pricing where only fragmented supply chains emerged for industries with an emission intensity between $\underline{\alpha}$ and $\bar{\alpha}$, in a border tax regime all industries produce entirely domestically. 
Figure 2 shows the consequences for the industry structure over the good space $z$ for $N$ industries that are active on $S$ markets.

Insight 5. The effects of a border tax on imported embodied emissions by $N$ to supplement unilateral emission pricing are ambiguous: On the one hand, the border tax regime in $N$ makes more integrated industries competitive and suppresses the offshoring of upstream production of industries between emission intensities $\underline{\alpha}$ and $\hat{\alpha}$. But on the other hand, North looses competitiveness due to higher costs of intermediates for the more energyintensive industries $\hat{\alpha}$ and $\bar{\alpha}$.

With the change in the production setup, the presence of a border carbon tax also has effects on the amount and origin of emissions. For goods sold on markets in the regulated North the implications are straightforward: offshoring due to emissions regulation is not a profitable strategy anymore and leakage becomes irrelevant. But the situation is different for markets in the South, which now produces more for local markets.

Insight 6. On the one hand, border taxes by $N$ reduce emissions because upstream processes are brought back to $N$ and $N$ produces cleaner than $S$ due to higher emission costs. On the other hand, other industries now also move their downstream stages $S$ and thus increase the emissions. Depending on which of the effects is dominating, the border tax can also increase carbon leakage.

\section{Quantitative Assessment of Complex Supply Chains}

The above described analytical partial equilibrium framework revealed several important insights about the effect of unilateral regulation on the fragmentation of supply chains. However, the model offered only a stylized representation of supply chain management and ignored at least five important dimensions due to trade-offs with analytical tractability. In this section, we extend the illustrative framework first and foremost to a general equilibrium representation that includes interdependencies of factor and good markets. Thus, supply chain adjustments may interact with each other. Second, we study trade and offshoring relationships in a universe consisting of more than two regions. Third, final goods are produced in more than two stages and their production can span over multiple regions. Fourth, an intermediate good may be used in several industries, so supply 
chains are not straight lines but complex interweaved networks of sectoral relationships. Fifth, also the representation of industries is more complex. They vary not only their emission-intensity but also in their ability to change the source of their upstream inputs, their ability to substitute in the production process the intermediates with factor input, and their intensity of upstream intermediate goods use.

\subsection{Model Structure}

To account for the aforementioned additional aspects and to quantify the effects of unilateral regulation on vertical specialisation, we apply for the first time a unique CGE model with an explicit specification of the origin as well as the destination of intermediate goods flows on a regional and sectoral level (for a general description of the model, see Koesler and Pothen (2013)).

Similar to our analytical model, production is modeled using constant elasticity of substitution (CES) functions, although more nuanced with heterogeneity among regions and industries regarding value shares and elasticities. The production of final output of sector $i$ in region $r$ is described by:

$$
y_{r, i}=\left[\theta_{r, i} x_{r, i}^{\rho_{r, i}^{l d x}}+\left(1-\theta_{r, i}\right)\left[\left(1-\alpha_{r, i}\right) l_{r, i}^{\rho_{r, i}^{l d}}+\alpha_{r, i} d_{r, i}^{\rho_{i, r}^{l d}}\right]^{\frac{\rho_{r, i}^{l d x}}{\rho_{r, i}^{l d}}}\right]^{\frac{1}{\rho_{r, i}^{l d x}}}
$$

Note that industries are no longer distributed continuously but are discrete and of finite number, indexed by $i$. Final output $y_{r, i}$ in industry $i$ from region $r$ is produced in a similar structure as in the analytical model. On the first stage, a production factor composite $l_{r, i}$ consisting of capital and labour is blended with a carbon-emitting energy input $d_{r, i}$, where $\sigma_{r, i}^{l d}=1 /\left(1-\rho_{r, i}^{l d}\right)$ denotes the elasticity of substitution between these two inputs. Each sector uses a fixed mix of energy sources, each with a specific carbon emissions coefficient. Note that in contrast to the analytical model, also process emissions - a fixed byproduct of sectoral production - are taken into account and affect the emission intensity of a sector. On the second stage, the composite of factors of production and energy is combined with a bundle of intermediate goods $x_{r, i}$ sourced from other sectors, where $\sigma_{r, i}^{l d x}=1 /\left(1-\rho_{r, i}^{l d x}\right)$ denotes the elasticity of substitution between these two inputs. In contrast to the analytical model, we account now for more complex production structures and consider intermediates from various sectors. However, we assume that the mix of 


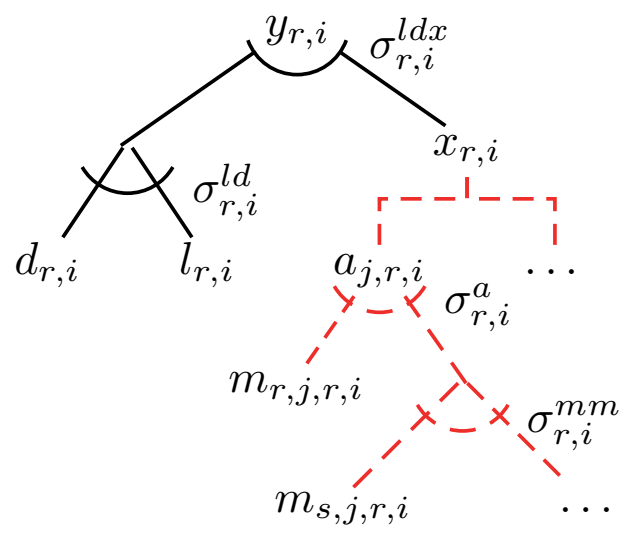

Figure 3: Production structure model of sector $i$ in the CGE model. Dashed lines indicate the extensions to the analytical model.

intermediates remains constant.

Each intermediate good $a_{j, r, i}$ used in sector $i$ in region $r$ consists of a combination of domestic and foreign final inputs from sector $j$. While in the analytical model it has been assumed that goods from different origin are perfect substitutes, now goods of different origin are assumed to be only imperfect substitutes (Armington 1969), with an elasticity of substitution parameter between domestic and foreign output $\rho_{r, i}^{a}$ and between different foreign regions $\rho_{r, i}^{m m}$. Eventually, each intermediate input $a_{j, r, i}$ arises from

$$
a_{j, r, i}=\left(\beta_{j, r, i} m_{r, j, r, i}{ }^{a}{ }_{r, i}+\left(1-\beta_{j, r, i}\right)\left(\sum_{s \forall s \neq r} \gamma_{s, j, r, i}\left(m_{s, j, r, i}\right)^{\rho_{r, i}^{m m}}\right]^{\frac{\rho_{r, i}^{a}}{\rho_{r, i}^{m}}}\right)^{\frac{1}{\rho_{r, i}^{a}}},
$$

where $\beta_{j, r, i}$ indicates sector $i$ in region $r$ 's share of domestic intermediates from sector $j$ and $\gamma_{s, j, r, i}$ is the respective share of intermediate $j$ sourced from region $s$. Note that in contrast to most other CGE models, WIOD enables to model Armington bundles specific for each sourcing sector. This additional structure not only allows to trace sectoral supply chains more detailed but also creates additional variation in sectoral supply chain adjustments as responses to the examined policy interventions. The overall production structure of the CGE model and an illustration of how this relates to the analytical model is presented in Figure 3.

Similar to the analytical model, a purchasing manager has two options if emitting carbon becomes more expensive: On the one hand, she can replace energy with domestic production factors. This 'direct abatement action' increases the intensity of domestic 
production factors and hence reduces vertical specialisation indirectly. On the other hand, she can offshore production to non-regulated regions by increasing the use of intermediates from those regions. This mirrors what has been defined as vertical specialisation at the intensive margin above. Depending on the respective input intensities and elasticities of substitution, one of the two effects dominates and governs changes in the composition of the supply chain. As it can be seen from Table 1, industries vary substantially in their pre-policy input intensity of foreign intermediate use. Later, we identify this as the main source in sectoral heterogeneous policy responses on the structure of supply chains.

Each region is represented by one aggregated representative agent who determines final demand. The representative agent maximises her utility by purchasing bundles of consumption goods subject to her budget constraint that equals factor income. Regarding the final demand structure, we follow Herrendorf, Rogerson, and Valentinyi (2013) and assume that utility of the representative agent is defined as a Leontief composite of all final goods. Her budget is determined by factor and tax income and she supplies the factors of production. These factors are mobile across sectors within regions but not across regions. Further details on the CGE model are presented in the Appendix.

\subsection{Data, Calibration and Aggregation}

The model is calibrated to the year 2005 with the WIOD dataset. ${ }^{8}$ WIOD provides an annually consistent representation of the world economy and contains production, trade and emissions data for 35 sectors of 27 member states of the European Union plus 13 other major economies.

The originally 40 economies included in WIOD are aggregated to eight regions. Table 3 in the Appendix shows the regional aggregation in detail. Some model regions are large countries, such as China or the United States; others are multi-country regions such as the European Union (EU). The primal 35 sectors are aggregated to 18 sectors, details are given in Table 4 in the Appendix. We focus on sectors where cross-border supply chains are expected to be more relevant, such as in manufacturing. Thereby, we broaden the picture generally drawn by the literature and not only consider the output when assessing the

\footnotetext{
${ }^{8}$ See Timmer, M. et al. (2012) and Dietzenbacher, Los, Stehrer, Timmer, and de Vries (2013) for an extensive description of the dataset that can be downloaded at http://www. wiod.org. Data downloaded on the 17th of April 2013 has been used for this analysis.
} 
trade exposure of a sector but also its inputs and the sourcing of upstream intermediates. Since service sectors have neither a high emission intensity nor have particularly intense cross-border supply chains, several service sectors have been aggregated. Furthermore we distinguish between three types of energy which are sourced from the three WIOD sectors "coke, petroleum, nuclear fuel" (COPN), "mining and quarrying" (MINI), and "electricity, gas, water supply" (ELGW).

For substitution elasticities determining the flexibility of production with regard to inputs, estimates from Koesler and Schymura (forthcoming) are applied which are estimated from the same data the model is also calibrated to. The average elasticity of substitution between value-added and energy $\left(\sigma_{(r, i)}^{\mathrm{ld}}\right)$ is 0.4 , the minimum (maximum) is 0.1(1.1). ${ }^{9}$ The average substitutability between the value-added-energy composite and material $\left(\sigma_{(r, i)}^{\mathrm{ldx}}\right)$ is 0.6 and varies from 0.1 to 2.3. An overview of the different elasticities is also given in Table 1. The Armington elasticities required by the model are taken from GTAP7 (Badri and Walmsley 2008, Hertel, Hummels, Ivanic, and Keeney 2007, Hertel, McDougall, Narayanan, and Aguiar 2008) and mapped to WIOD sectors. The average elasticity between domestic and foreign goods $\left(\sigma_{r, i}^{\mathrm{a}}\right)$ is 3.1 and varies between 1.6 and 4.4, while the elasticity for the regional allocation of inputs $\left(\sigma_{r, i}^{\mathrm{mm}}\right)$ is 6.2 and ranges from 3.1 to 8.8 .

\subsection{Benchmark Situation}

We define the degree of vertical specialisation of an industry as the foreign factor content that is not related to energy consumption per unit of output, corresponding to our definition above. Note that due to the Armington trade structure a discrete offshoring of entire production stages to non-regulated regions - defined in the analytical model as vertical specialisation at the extensive margin - is ruled out. To compute the quantity of factor content and later the amount of carbon embodied in sectoral output, we follow the Multi-Region Input-Output (MRIO) literature (Peters 2008) and construct first an input coefficient matrix A building on the multi-regional Input-Output Table provided by WIOD:

\footnotetext{
${ }^{9}$ Note, Koesler and Schymura (forthcoming) do not provide a reliable $\sigma_{(r, i)}^{\text {ld }}$ for the Coke, Refined Petroleum. and Nuclear Fuel (CPN) sector. We assume that this elasticity is equal to the corresponding elasticity of the chemical sector (0.717).
} 


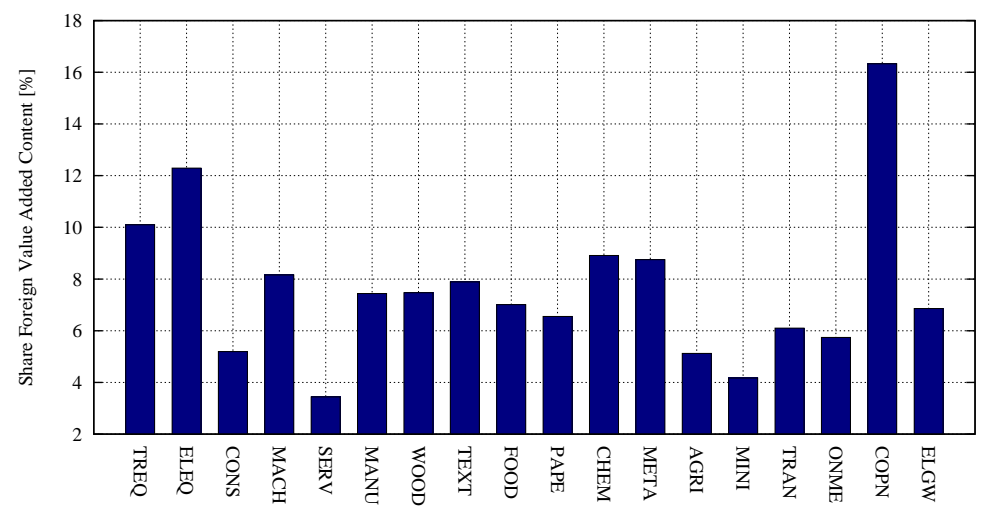

Figure 4: Fraction of foreign non-energy factor content in 2005 for 18 European sectors.

$$
\mathbf{A}=\left(\begin{array}{ccc}
\iota_{s, j, s, j} & \ldots & \iota_{s, j, r, i} \\
\vdots & \ddots & \vdots \\
\ldots & \ldots & \iota_{r, i, r, i}
\end{array}\right)
$$

with $\iota_{s, j, r, i}$ as the input coefficient describing the use of good $j$ in region $s$ in sector $i$ in $r$. The Leontief inverse $(\mathbf{I}-\mathbf{A})^{-1}$ of $\mathbf{A}$ then provides all necessary information on the structure of supply chains for all sectors in all regions. Multiplying the Leontief inverse with a vector of factor content or carbon intensity and a vector of total sectoral output subsequently allows to calculate the amount of non-regulated foreign factor or carbon embodied in domestic output.

Figure 4 shows the foreign factor content in the output of European sectors in the year 2005. The content varies from 3.4 percent in the service sector (SERV) to 16.3 percent in the energy intensive sector of coal, petroleum and nuclear (COPN) production. Apart from services, sectors characterised with a low degree of fragmentation are upstream sectors such as mining and quarrying (MINI), agriculture (AGRI) and construction (CONS). More fragmented are on the one hand manufacturing sectors such as the production of electronic equipment (ELEQ), transport equipment (TREQ), and machinery (MACH). On the other hand, also European basic material sectors such as metals (META) and chemicals (CHEM) are characterised with a high foreign factor content. But the two groups differ in their emission intensity: Whereas ELEQ, TREQ, and MACH are sectors with low emission intensity, META and CHEM emit are relatively carbon-intensive in the production process. 


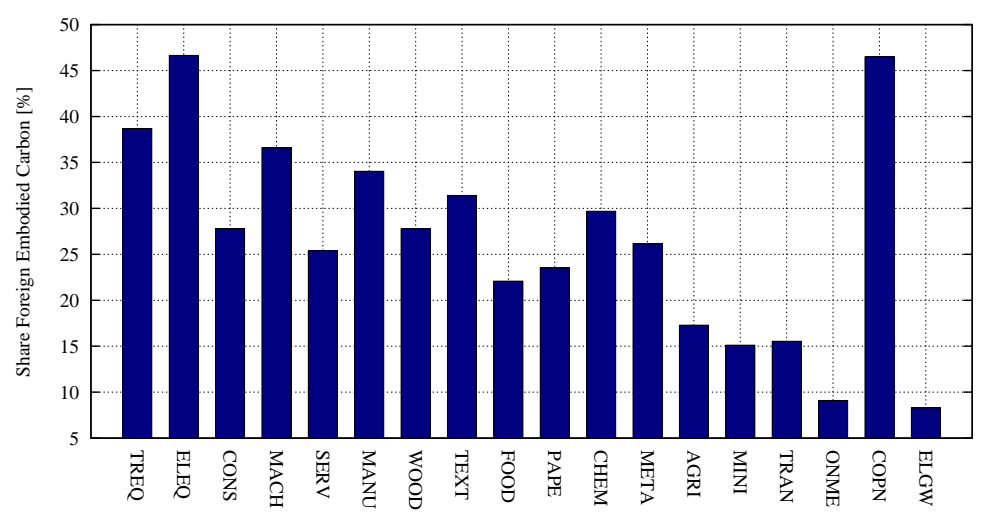

Figure 5: Fraction of foreign carbon content in 2005 for the 18 European sectors.

Obviously, not only value added has been collected along the supply chain but often also emissions. Figure 5 illustrates the amount of foreign carbon embodied in EU sectoral output. Its foreign carbon share ranges from 10.7 (ELGW) percent to 56.4 (ELEQ) percent. In particular the European sectors that produce coke, petroleum and nuclear fuel, but also electrical equipment - the most fragmented sector - contain high shares of foreign embodied carbon. But note that both sectors feature very different absolute values in embodied carbon. Sectors with only little foreign carbon embodied in their production are the sectors associated to electricity gas and water supply (ELGW) as well as non-metallic minerals such as cement where a large part of emission is added during the last production stage.

\subsection{Simulation Results}

To quantify the magnitude of the effects identified in the analytical model, we study two policy scenarios that correspond to the previous analysis. In the first scenario it is assumed that the EU commits itself to unilaterally reduce its carbon emissions by 20 percent relative to baseline of 2005 . Thereby we assume that the required emission reductions within the EU are granted by an ETS with full auctioning encompassing emissions in all sectors. This can be seen as a stylized replication of EU 2020 climate policy, that aims at reducing GHG emissions by 20 percent relative to the 1990 level by $2020 .{ }^{10}$ In other regions, no emission reduction regulations are in place.

\footnotetext{
${ }^{10}$ For an more comprehensive assessment of this policy, see Böhringer, Löschel, Moslener, and Rutherford (2009).
} 
Table 1: Input content and elasticities of European production in benchmark

\begin{tabular}{lrrrrrrrrr}
\hline Sector & $\mathrm{CO}_{2}\left[\frac{g}{U S D}\right]$ & VA [\%] & E[\%] & NEG[\%] & FNEG[\%] & $\sigma^{l d}$ & $\sigma^{l d x}$ & $\sigma^{a}$ & $\sigma^{m m}$ \\
\hline TREQ & 15.36 & 23.49 & 1.50 & 75.01 & 6.38 & 0.16 & 0.38 & 3.55 & 7.10 \\
ELEQ & 17.70 & 33.77 & 1.54 & 64.69 & 10.42 & 1.06 & 0.64 & 4.40 & 8.80 \\
CONS & 21.36 & 40.19 & 2.03 & 57.78 & 2.44 & 0.15 & 0.61 & 1.90 & 3.80 \\
MACH & 23.53 & 36.01 & 1.76 & 62.22 & 5.43 & 0.20 & 0.55 & 4.05 & 8.10 \\
SERV & 26.78 & 61.01 & 1.57 & 37.42 & 2.02 & 0.27 & 1.48 & 1.57 & 3.13 \\
MANU & 39.66 & 34.50 & 2.23 & 63.27 & 4.72 & 0.18 & 0.53 & 3.75 & 7.50 \\
WOOD & 53.07 & 32.48 & 2.98 & 64.54 & 4.43 & 0.21 & 0.71 & 3.40 & 6.80 \\
TEXT & 61.25 & 32.28 & 2.73 & 64.98 & 5.36 & 0.26 & 0.58 & 3.79 & 7.58 \\
FOOD & 62.86 & 26.77 & 2.67 & 70.56 & 3.93 & 0.19 & 0.63 & 3.00 & 6.00 \\
PAPE & 82.14 & 37.86 & 3.42 & 58.72 & 4.08 & 0.25 & 0.66 & 2.95 & 5.90 \\
CHEM & 168.55 & 32.57 & 6.50 & 60.94 & 6.64 & 0.57 & 0.87 & 3.30 & 6.60 \\
META & 272.96 & 32.53 & 6.64 & 60.83 & 6.02 & 1.01 & 0.11 & 3.75 & 7.50 \\
AGRI & 217.97 & 49.51 & 4.67 & 45.82 & 2.83 & 0.40 & 0.98 & 2.50 & 5.00 \\
MINI & 338.43 & 61.95 & 11.02 & 27.00 & 2.16 & 0.42 & 0.22 & 4.12 & 8.25 \\
TRAN & 348.12 & 43.76 & 5.38 & 50.85 & 3.42 & 0.48 & 0.45 & 1.90 & 3.80 \\
ONME & 940.16 & 37.45 & 12.70 & 49.85 & 2.82 & 0.25 & 0.81 & 2.90 & 5.80 \\
COPN & 533.54 & 12.25 & 59.47 & 28.27 & 9.81 & 0.72 & 0.42 & 2.10 & 4.20 \\
ELGW & 1948.75 & 40.55 & 35.03 & 24.42 & 3.10 & 0.46 & 0.68 & 2.80 & 5.60 \\
\hline
\end{tabular}

Input content from WIOD and elasticities from Koesler and Schymura (forthcoming) ( $\sigma^{l d}$, $\left.\sigma^{l d x}\right)$ and Badri and Walmsley $(2008)\left(\sigma^{a}, \sigma^{m m}\right)$.

VA: value-added, E: energy, NEG: non-energy intermediates, FNEG: foreign non-energy intermediates, $\sigma^{l d}$ : substitution elasticity between factor input and energy, $\sigma^{l d x}$ : substitution elasticity between factor-energy composite and intermediate composite, $\sigma^{a}$ : Armington elasticity between domestic and foreign goods, $\sigma^{m m}$ : Armington elasticity between goods from different foreign regions. 
In the second policy scenario, we supplement the unilateral domestic climate policy of the EU by a border tax on all carbon that is embodied in imports into the EU. Embodied carbon is calculated by taking into account the carbon emitted along the supply chain when entering the jurisdiction of the EU and descending from non-regulated regions. Thus, we account for a possible multi-regulation of emissions at different production stages of a good. The imported embodied carbon is priced according to the prevailing price of carbon in the ETS regulating EU emissions. The introduction of a border tax in turn implies that carbon emissions arising in non-EU regions also become costly if they are imported into the EU.

\subsubsection{Unilateral Carbon Pricing}

Figure 6 shows how foreign factor content in the 18 different sectors of our EU economy change under the two scenarios. As in the analytical framework, sectors are ranked according their emission intensity. The unilateral European policy to reduce carbon emissions by 20 percent (Figure 6a) indeed alters the sourcing of intermediates in European sectors. The median increase in vertical specialisation is 3.3 percent. In particular industries with a high emission intensity such as as electricity, gas and water supply (ELGW, $+21.2 \%$ ), the production of metal products (META, $+8.5 \%$ ) or other non-metallic minerals (ONME, $+13.1 \%$ ) are becoming more dependent on foreign intermediates and more vertically specialised. To a smaller extent, but due to the size of the sectors also important, the European chemical industries (CHEM, +3.9\%) and manufacturing (MANU, $+3.2 \%$ ) offshore production capacities to non-regulated regions and increase the share of non-European value added in their final output. Several industries - such as services (SERV, -3.1\%) or electrical equipment (ELEQ, -1.5\%) - become less fragmented and reduce the use of foreign input. In general the results from the more complex calibrated CGE model reflect the Insight 2 derived from the analytical model.

But including additional data on the sectoral structure - differences in elasticities of substitution and heterogeneous value shares - leads to a more complex picture. In order to decompose the sector's offshoring reactions to the policy interventions, we leave for a moment the general equilibrium perspective and turn our attention again to the crossprice elasticity of domestic energy with regard to foreign factor content. To keep this analytically tractable we have to work with several simplifying assumptions that become 


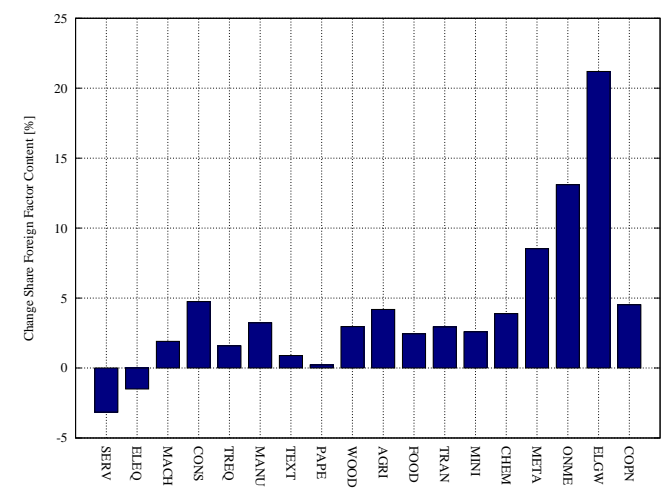

(a) Unilateral carbon pricing

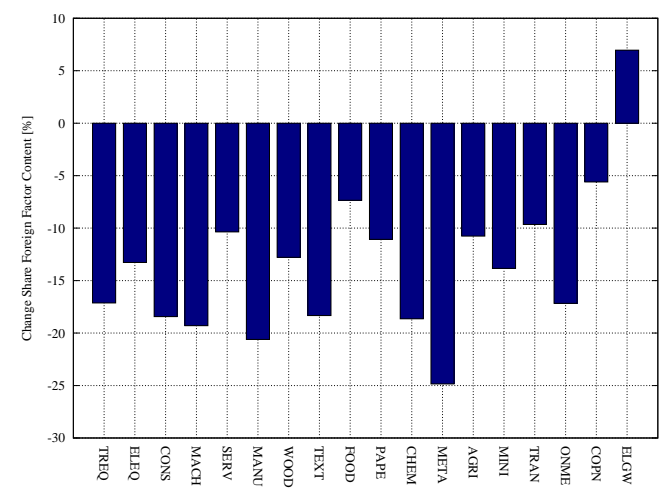

(b) Unilateral carbon pricing

and border tax

Figure 6: Changes in vertical specialisation for European sectors relative to benchmark scenario for the two scenarios.

resolved when turning back to the numerical model. We use energy price changes as a proxy for carbon price changes, assuming that a marginal carbon price change leads to an identical energy price change in each sector, thus neglecting sector differences in the energy composition as well as process emissions. Further, we only consider the last two stages in the supply chain.

The cross-derivative can be computed using the calibrated demand function for foreign value added embodied in upstream intermediates of sector $i$ in region $r$ and then take the derivative with respect to domestic energy price change. The cross-price elasticity $\chi_{r, i}^{l_{s}}$ consists of two components: The first component captures the change in foreign factor content induced by a energy price change in the final stage. The second component captures the shift to foreign factor content induced by a price change of domestic energy in upstream intermediate goods.

$$
\begin{aligned}
\chi_{r, i}^{l_{s}} & =\sum_{j} \sum_{s} \frac{\partial l_{r, i, s, j}}{\partial p_{r, i}^{e}} \frac{p_{r, i}^{e}}{l_{r, i, s, j}}=\left(1-\theta_{r, i}\right) \alpha_{r, i} \sigma_{i}^{l d x} \\
& +\sum_{j} \sum_{s} \theta_{r, i} \beta_{j, r, i}\left(1-\theta_{s, j}\right) \alpha_{s, j}\left[\sigma_{j}^{l d x}-\frac{\sigma_{j}^{l d x}}{\theta_{r, i}}+\frac{\sigma^{a}}{\theta_{r, i}\left(1-\beta_{j, r, i}\right) \alpha_{s, j}}\right],
\end{aligned}
$$

where $l_{r, i, s, j}$ describes the foreign factor content finally used in the last production stage of sector $i$ in region $r$, sourced from region $s$ and sector $j$ and $p_{r, i}^{e}$ is the price index of the energy bundle used in sector $i$ in region $r$. 
The first component, the direct offshoring effect is increasing in energy-intensity of the sector and the elasticity of substitution between energy and value added, similar to the analytical model (see Insight 2). The second component describes the shift from domestic to foreign intermediates if the domestic energy price increases.

The different panels in Figure 7 depict the calibrated cross-price elasticities and illustrate how the offshoring response evolves when adding additional structure to sector's characteristics. The first panel (a) assumes that as in the analytical model, energyintensity increases linearly between sectors. The second panel (b) shows offshoring reactions when sectors differ in their energy-intensity, now calibrated with WIOD data and assuming all other input intensities and elasticities are equal across sectors. The third panel (c) additionally includes data on the sectoral and regional heterogeneity in the intensity of intermediates use. Finally, the last panel (d) in Figure 7 accounts for further differences in the elasticities of substitution.

With an increase in vertical specialisation of 4.5 percent in the CGE runs, the coke, petroleum and nuclear fuel sector (COPN) for example features a lower offshoring response than one would have expected given its relatively high level of energy intensity. Studying the associated cross-price elasticity reveals that its relatively high share of foreign intermediate moderates the policy impact to this sector. Accordingly, incorporating sectoral differences in the benchmark sourcing of intermediates in the calibration of the production functions leads to a drop in the cross-price elasticity under scrutiny.

However, the decrease in vertical specialisation of the service (SERV) and electrical equipment (ELEQ) sector cannot directly be explained by differences in cross-price elasticities. Both sectors are characterized by a particularly low energy and emission intensity and are directly only slightly affected by the higher energy costs. In addition, both sectors are relatively value added intensive and benefit from the decrease in the price of value added $(-4.7 \%)$ that follows the implementation of the emission reduction policy in Europe. So eventually also general equilibrium effects that resonate through the economy have an important impact on the structure of supply chains and should be considered when studying the vertical specialisation effects of policies.

Obviously, changes in the vertical structure of an industry and the respective supply chain adjustments also lead to changes in the amount and source of emissions embodied in an industries' output. We measure the change in the origin of carbon that is embodied 


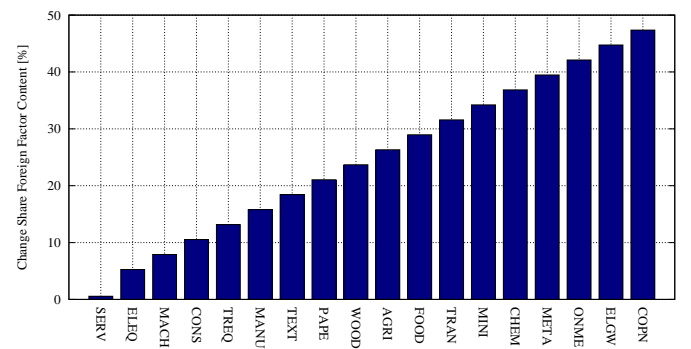

(a)

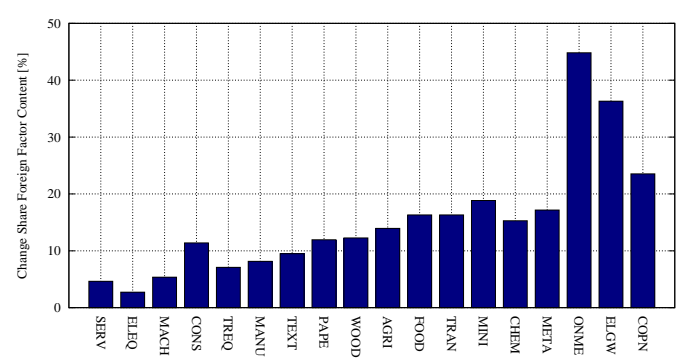

(c)

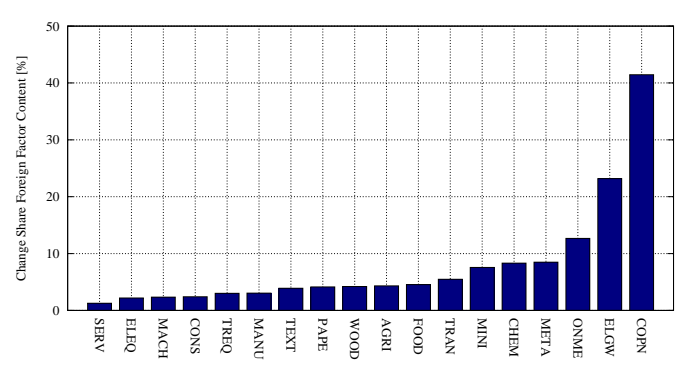

(b)

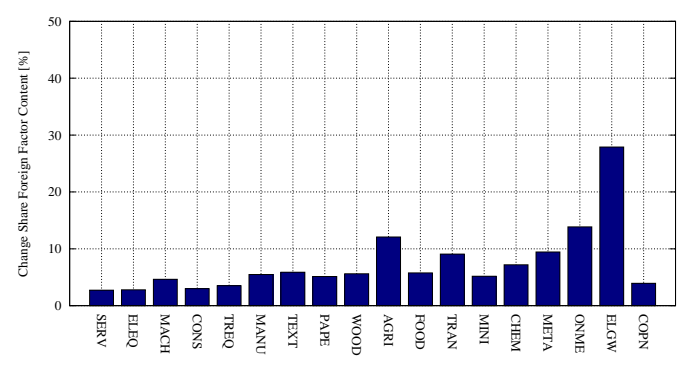

(d)

Figure 7: Cross-price elasticities of demand for foreign value added with regard to changes in European energy prices parameterised with different values for input intensities. Panel (a) assumes that energy intensity increases linearly from sector to sector and that sectors are otherwise the same. Panel (b) accounts for actual differences in the energy intensity of EU sectors. Panel (c) adds structure regarding the origin of foreign intermediate intensity. Panel (d) further accounts for estimated elasticities. 


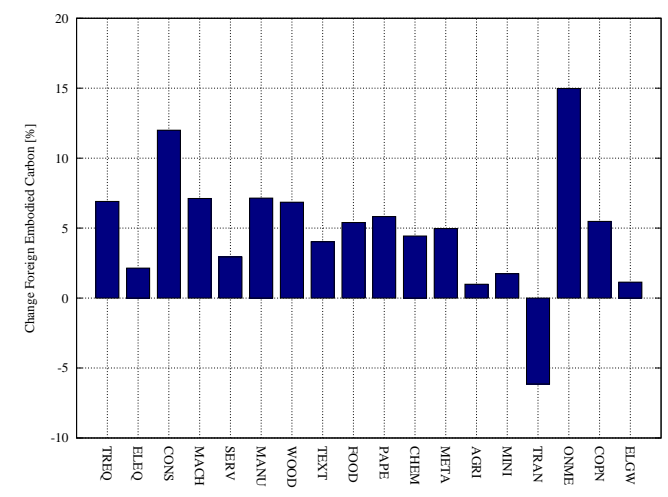

(a) Unilateral carbon pricing

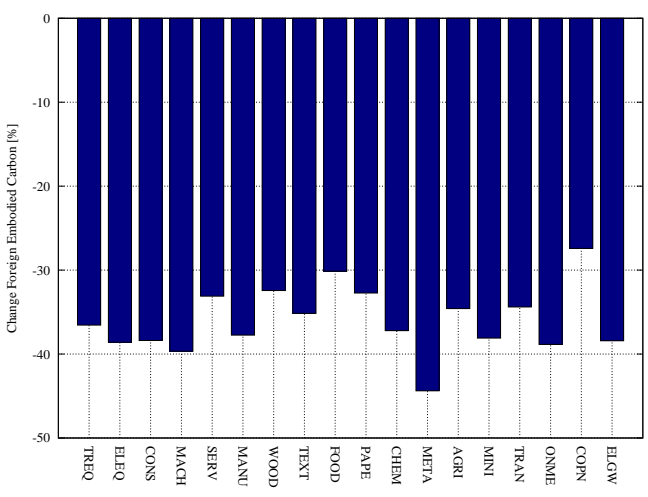

(b) Unilateral carbon pricing

and border tax

Figure 8: Changes of foreign embodied carbon in European output relative to Benchmark.

in a unit of output as:

$$
\Delta C_{i}^{\mathrm{EU}}=\frac{\Delta e c_{i}^{\mathrm{NoEU}}}{\Delta e c_{i}^{\mathrm{EU}}},
$$

where $\Delta e c_{i}^{\mathrm{NoEU}}$ is the change in embodied carbon from non-European sources and $\Delta e c_{i}^{\mathrm{EU}}$ the change in embodied carbon from European sources, both in output of industry $i$ relative to the Benchmark. Note that an increase of non-European carbon embodied in European output due to lower prices of non-European energy intensive intermediates is one part of what generally encompasses carbon leakage. The change in the origin of carbon in non-European industries' supply chains is presented in Figure 8. All sectors apart of the transportation sector (TRAN) increase the amount of embodied carbon from non-EU regions.

Unilateral Emission Pricing with Border Emission Taxes Changes in composition of the supply chain if the EU's domestic carbon pricing is complemented by a border tax on all carbon that is embodied in imports into the EU are shown in Figure 6b. With a median decrease of 13.6 percent, vertical specialisation drops significantly for virtually all industries. The strongest drop takes place in metal production (META, -24.9\%), which in Europe relies heavily on carbon intensive intermediate inputs from abroad. The sector with the smallest but still very much noticeable drop of 7.0 percent is the sector related to the supply of coke, petroleum and nuclear products (COPN).

According to our Insight 5 , the introduction of a border carbon tax in the EU reduces 


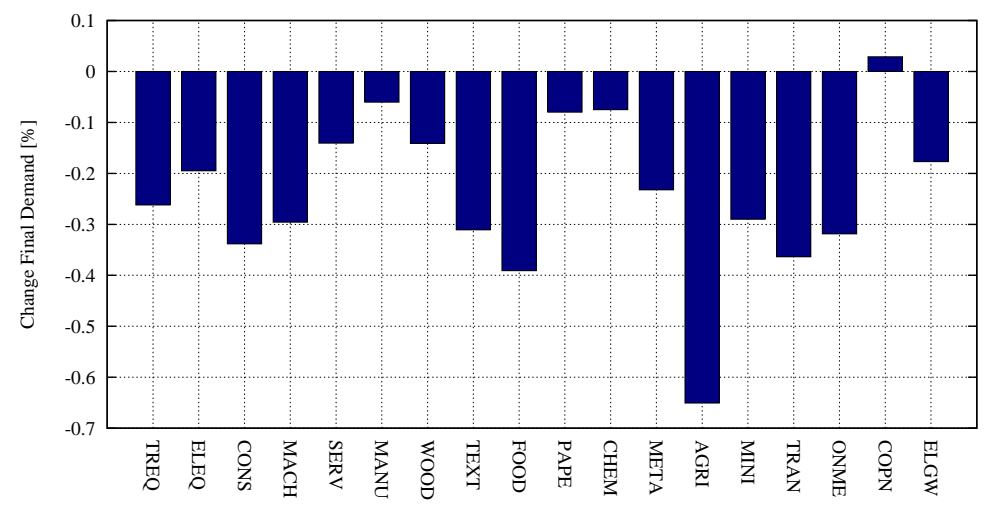

Figure 9: Changes in sales of European goods to final consumers in all other non-regulated regions with border taxes relative to the scenario with only European unilateral emission pricing.

the competitiveness in foreign markets for industries that depend on foreign emissionintensive intermediates. The border tax increases the costs of these goods, leading to sales losses in foreign regions since consumers switch to goods from producers with untaxed supply chains. Figure 9 shows similar findings that emerge from the CGE model. Virtually all European sectors face a reduction in final demand in non-regulated regions (Median $-0.25 \%$ ). The most affected sector is agriculture (AGRI, -0.65\%). The negative effect is stronger for goods where non-EU carbon is embodied to a larger extent, that is for example electrical or transport equipment (ELEQ,-0.19\%; TREQ, -0.26\%).

\subsubsection{General Impacts of the Policies}

After having focused on the consequences of unilateral climate policy on the vertical structure of EU industries we turn now our attention towards the general implications of those policies. Table 2 summarizes the change in key economic indicators for the EU. If the EU reduces its emissions unilaterally, GDP in the EU falls by 0.48 percent and welfare, measured in Hicksian equivalence, drops by 0.50 percent. Imports and exports are reduced by 4.63 percent and 4.25 percent, respectively.

The observed carbon leakage rate of 39 percent is relatively high, but consistent with findings from Bednar-Friedl, Schinko, and Steininger (2012) who also account for process emissions. Besides the EU, in particular Russia and ROW are negatively affected by the EU policy seeing their GDP fall by 0.40 percent and 0.19 percent, respectively. Their 
Table 2: Summary of change in key economic indicators in the EU [\%]

\begin{tabular}{lrr}
\hline & $\begin{array}{r}\text { Unilateral emission } \\
\text { pricing }\end{array}$ & $\begin{array}{r}\text { Unilateral emission } \\
\text { pricing and border tax }\end{array}$ \\
\hline GDP & -0.48 & -0.38 \\
Exports & -4.25 & -21.79 \\
Imports & -4.63 & -22.08 \\
Welfare & -0.50 & -0.31 \\
Carbon leakage & 39.46 & 25.75 \\
\hline
\end{tabular}

welfare decreases by 0.40 percent and 0.14 percent, respectively, mainly caused by a drop in energy exports of these regions to the EU.

The implementation of a border carbon tax eases the effect of the unilateral carbon pricing in the EU. GDP losses amount 0.38 percent only while welfare falls by 0.31 percent relative to our no-policy baseline. But it comes at the cost of strong reductions in exports $(-21.79 \%)$ and imports $(-22.08 \%)$, as decribed in Insight 4 . The border tax, however, reduces carbon leakage by almost 14 percentage points. Thus, the theoretically possible outcome that a border tax induces sufficient large offshoring such that carbon leakage increases, as described in Insight 5, can not be observed within the calibrated parameter values. The border carbon tax leads shifts the burden of climate policy between regions. Under a sole unilateral carbon price, the EU bears the majority of policy costs. But the carbon tax results shifts the burden to the exporters of energy and energy-intensive goods to the EU. As a result, a EU border carbon tax reduces Russia's welfare by more than 4 percent. But also China is significantly affected, coping with welfare losses of 1 percent.

\section{Summary and Conclusion}

The evolution of global supply chains reshapes the economic landscape with consequences for the effectiveness of unilateral environmental regulations. We analyse the general mechanism of offshoring fragments of the supply chain due to unilateral regulation in the form of emission pricing and an import tax of embodied emissions with an analytical partial equilibrium model of a two stage production process that can be distributed between two regions. With this simplified model at hand, we are able to distinguish between offshoring 
at the extensive margin, i.e. the fragmentation of the supply chain by offshoring entire production stages to unregulated regions, and offshoring at the intensive margin, which captures changes in foreign factor content in domestic industries.

We find that unilateral emission reduction polices force more emission-intensive producers to offshore a greater part of their supply chain to the unregulated region and thereby increasing vertical specialisation at the extensive as well as at the intensive margin. Border carbon taxation in turn is successful in fetching these stages back home. But with the negative side effect that it may also force some industries that depend on energy-intensive upstream inputs to move entirely to unregulated regions.

In reality, though, the production network is far more complex and interweaved between sectors. Therefore, we extend next the analysis to a full-fledged CGE model that is calibrated using WIOD data and investigate the implications of an unilateral carbon reduction policy by the EU. Overall, the findings of the CGE model corroborate the theoretical analysis. But as input-intensities and elasticities of substitution determine the offshore opportunities, the magnitudes of offshoring responses vary across sectors.

When the EU unilaterally implements a 20 percent reduction in emissions, sectors increase vertical specialisation by up to 21 percent, whereas the median sector increases its degree of vertical specialisation by about 3 percent. While overall carbon leakage amounts to 39 percent, changes in the supply chain of sectors cause an increase in embodied carbon from non-European sources for most industries. If the EU complements its unilateral reduction policy with a border tax on all imported embodied carbon, offshoring is stopped. On the contrary, in such a situation supply chains shrink notably and as a side effect EU sectors loose market shares in foreign markets since their input-intensive industries loose competitiveness.

Overall, our study reveals that unilateral regulation may have effects on the production structures of industries and complement other drivers such as transportation costs in shaping the global supply chains. Production relocation also has implications on the overall emission-intensity of the good. Hence, researchers and policy makers alike should not only consider direct effects such as the trade exposition of sectors when discussing unilateral policy measures but also include less tangible but still important effects on the composition of global supply chains..

However, in order to be able to assess these effects comprehensively, more research 
is necessary. It is particularly important to better understand how supply chains can be fragmented and offshored, and how much flexibility industries have to adjust their supply chains. Hence, better data is needed, in particular global multi-regional input output datasets with a higher sectoral resolution. In addition, the interaction of the different drivers of vertical specialisation such as unilateral policy, energy prices, and transport costs needs further research in order to be able to derive better indications of how supply chains response to policy changes. Fragmentation also often means more transport and thus more emissions. This nexus is also important for a comprehensive inclusion of global supply chain behavior that is necessary in order to design effective and efficient environmental regulations.

\section{Acknowledgments}

Oliver Schenker gratefully acknowledges the support from the German Federal Ministry of Education and Research within the Call "Ökonomie des Klimawandels" (funding code 01LA1105B: Climate Policy and the Growth Pattern of Nations (CliPoN)). Simon Koesler and Andreas Löschel gratefully acknowledge the support of the the 7th EU-framework project "WIOD: World Input-Output Database: Construction and Applications" under Theme 8: Socio-Economic Sciences and Humanities, Grant agreement no. 225 281. We thank Carolyn Fischer, Hermann Held, and Glen Peters for discussions and suggestions. The paper benefited also from discussions at presentations at the final conference of the WIOD project in Groningen, the MCC in Berlin, ZEW, RFF in Washington, the EAERE 2013 meeting in Toulouse, the AERE 2013 meeting in Banff, and the University of Hamburg. The authors claim responsibility for all errors and shortcomings herein.

\section{References}

Armington, P. S. (1969): "A Theory of Demand for Products Distinguished by Place of Production," IMF Staff Papers, 16(1), 159-178.

Badri, N. G., And T. L. Walmsley (2008): "Global Trade, Assistance, and Production: The GTAP 7 Data Base," Discussion paper, Center for Global Trade Analysis, Purdue University. 
Baldwin, R., And J. Lopez-Gonzalez (forthcoming): "Supply-chain Trade: A Portrait of Global Patterns and Several Testable Hypotheses," The World Economy.

Bednar-Friedl, B., T. Schinko, and K. W. Steininger (2012): "The relevance of process emissions for carbon leakage: A comparison of unilateral climate policy options with and without border carbon adjustment," Energy Economics, 24(S2), S168-S180.

Benarroch, M., and R. Weder (2006): "Intra-industry trade in intermediate products, pollution and internationally increasing returns," Journal of Environmental Economics and Management, 52(3), $675-689$.

Böhringer, C., A. Löschel, U. Moslener, and T. F. Rutherford (2009): "EU climate policy up to 2020: An economic impact assessment," Energy Economics, 31, Supplement 2(0), S295 - S305, International, U.S. and E.U. Climate Change Control Scenarios: Results from EMF 22.

Copeland, B. R. (1996): "Pollution content tariffs, environmental rent shifting, and the control of cross-border pollution," Journal of International Economics, 40(3-4), $459-476$.

Copeland, B. R., And M. S. Taylor (1994): "North-South Trade and the Environment," The Quarterly Journal of Economics, 109(3), 755-87.

Costinot, A., J. Vogel, and S. Wang (2012): "An Elementary Theory of Global Supply Chains," The Review of Economic Studies.

Dietzenbacher, E., B. Los, R. Stehrer, M. P. Timmer, and G. J. de Vries (2013): "The construction of world input-output tables in the WIOD project," Economic Systems Research, 25(1), 71-98.

Dietzenbacher, E., J. Pei, and C. YAng (2012): "Trade, production fragmentation, and China's carbon dioxide emissions," Journal of Environmental Economics and Management, 64(1), 88 - 101.

Dirkse, S. P., And M. C. Ferris (1993): The PATH Solver: A non-monotone stabilization scheme for mixed complementarity problems. Computer Sciences Department of the University of Wisconsin-Madison, Madison, USA. 
Dornbusch, R., S. Fischer, and P. Samuelson (1977): "Comparative advantage, trade, and payments in a Ricardian model with a continuum of goods," The American Economic Review, 67(5), 823-839.

Fischer, C., And A. K. Fox (2012): "Comparing Policies to Combat Emissions Leakage: Border Tax Adjustments versus Rebates," Journal of Environmental Economics and Management, 64, 199-216.

Grossman, G., and E. Rossi-Hansberg (2006): "The rise of offshoring: it's not wine for cloth anymore," The New Economic Geography: Effects and Policy Implications, pp. $59-102$.

(2008): "Trading Tasks: A Simple Theory of Offshoring," American Economic Review, 98(5), 1978-1997.

(2012): “Task trade between similiar countries," Econometrica, 80(2), 593-629.

Herrendorf, B., R. Rogerson, and K. Valentinyi (2013): "Two Perspectives on Preferences and Structural Transformation," American Economic Review, 103(7), 2752-89.

Hertel, T., D. Hummels, M. Ivanic, and R. Keeney (2007): "How confident can we be of CGE-based assessments of Free Trade Agreements?," Economic Modelling, $24(4), 611-635$.

Hertel, T., R. McDougall, B. Narayanan, and A. Aguiar (2008): "GTAP 7 Data Base Documentation - Chapter 14: Behavioral Parameters," Technical Report, Center for Global Trade Analysis, West Lafayette, USA.

Hummels, D., J. IshiI, And K. Yi (2001): "The nature and growth of vertical specialization in world trade," Journal of International Economics, 54(1), 75-96.

Koesler, S., And F. Pothen (2013): "The Basic WIOD CGE Model: A Computable General Equilibrium Model Based on the World Input-Output Database," ZEW Dokumentation 13-04, Zentrum für Europäische Wirtschaftsforschung (ZEW).

Koesler, S., and M. Schymura (forthcoming): "Substitution elasticities in a Constant Elasticity of Substitution framework - Empirical estimates using nonlinear least squares," Economic Systems Research. 
Markusen, J. R. (1975): "International externalities and optimal tax structures," Journal of International Economics, 5(1), 15-29.

McAusland, C. (2004): "Environmental regulation as export promotion: Product standards for dirty intermediate goods," Contributions to Economic Analysis and Policy, $3(2), 1-39$.

Peters, G. (2008): "From production-based to consumption-based national emission inventories," Ecological Economics, 65(1), 13-23.

Rutherford, T. F. (1999): "Applied General Equilibrium Modeling with MPSGE as a GAMS Subsystem: An Overview of the Modeling Framework and Syntax," Computational Economics, 14(1-2), 1-46.

Sturgeon, T. J., And O. Memedovic (2010): "Mapping Global Value Chains: Intermediate Goods Trade and Structural Change in the World Economy," Working Paper 05/2010, United Nations Industrial Development Organization.

Timmer, M. et AL. (2012): "The World Input-Output Database (WIOD): Contents, Sources and Methods," Discussion paper, University Groningen.

YI, K. (2003): "Can vertical specialization explain the growth of world trade?," Journal of Political Economy, 111(1), 52-102. 


\section{A Appendix}

\section{A.1 Proof Insight 3}

The cut-off determining the outsourcing of upstream production to $S$ as in condition (13) is:

$$
A^{1} \Gamma(z) \equiv \frac{A_{N}^{1}}{A_{S}^{1}}\left(\frac{\alpha(z) \tau_{N}+(1-\alpha(z)) \tau_{S}}{\tau_{S}}\right)^{\frac{1}{1-\alpha(z)}} \leq \frac{w_{N}}{w_{S}}\left(\frac{\tau_{N}}{\tau_{S}}\right)^{\frac{\alpha(z)}{1-\alpha(z)}} \equiv \omega T(z) .
$$

By assumption $A^{1} \geq \omega$. Thus, it becomes clear that $\Gamma(z) \leq T(z)$ must hold for (13) to hold. Since $0<\alpha(z)<1, \Gamma(z)$ can attain values in the interval $\lim _{\alpha(z) \rightarrow 0} \Gamma(z)=1$ and $\lim _{\alpha(z) \rightarrow 1} \Gamma(z)=\frac{\tau_{N}}{\tau_{S}}$.

At the lower bound of $\alpha(z)$,

$$
\lim _{\alpha(z) \rightarrow 0} \Gamma(z)=1<\lim _{\alpha(z) \rightarrow 0} T(z)=1
$$

must hold.

Since $\tau_{N}>\tau_{S},(23)$ never holds, at the upper bound of $\alpha(z)$

$$
\lim _{\alpha(z) \rightarrow 1} \Gamma(z)=\frac{\tau_{N}}{\tau_{S}}<\lim _{\alpha(z) \rightarrow 1} T(z)=\frac{\tau_{N}}{\tau_{S}}
$$

must hold.

Since $\tau_{N}>\tau_{S},(24)$ never holds for $\alpha(z)<1$, (13) can never hold either.

\section{A.2 Description of CGE Model}

In our numerical assessment we make use of an task specific version of the Basic WIOD CGE model. This model is a static, multi-region, multi-sector CGE model that has been designed in order to allow researchers to use the World Input-Output Database (WIOD) in a CGE model. A comprehensive description of this model is provided by Koesler and Pothen (2013).

The model we use in this analysis distinguishes between two groups of commodities: energy commodities $y_{r, e g}$ and non-energy commodities $y_{r, n e g}$. The production of these goods is characterised by production functions with constant elasticities of substitution (CES) and constant returns to scale. Nested CES functions with two levels are employed 


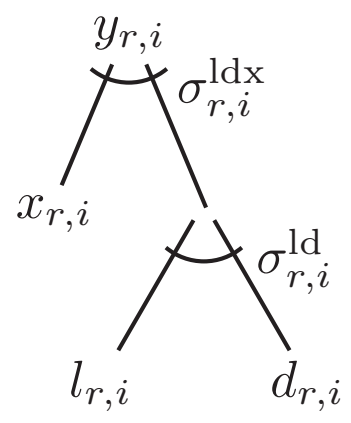

Figure 10: Structure of commodity production.

to specify the substitution possibilities between a factor composite $l_{r, i}$, energy $d_{r, i}$ and a non-energy intermediate composite $x_{r, i}$ of sectoral production. An overview of the production structure is given in Figure 10 and the corresponding zero-profit condition is given in Equation 25. Thereby and for all following CES functions, $\pi$ denotes profits. The arguments of the CES function is given in parentheses and the corresponding elasticity of substitution in the upper index. Small $p$ 's are prices of commodities and factors.

$$
\pi_{r, i}^{Y} \leq C E S_{r, i}^{\sigma_{r, i}^{l d x}}\left[p x_{r, i} ; C E S_{r, i}^{\sigma_{r, i}^{l d}}\left(p l_{r, i} ; p d_{r, i}\right)\right]
$$

Energy $d_{r, i}$ and the intermediate composite $x_{r, i}$ are a Leontief combination of energy commodities and non-energy commodities respectively.

Sectoral output can be used for intermediate use and/or final consumption domestically and/or exported to other regions. Perfect competition is assumed in all markets. The choice among imports and domestically produced commodities is based on Armington's idea of regional product differentiation (Armington 1969), i.e. domestic and foreign goods are not necessarily perfect substitutes and in combination form an Armington aggregate. In our setup however, Armington goods are not only region specific to account for regional differences in preference for domestic and foreign goods, but also sector specific in order to allow intermediates to be traced from their origin to their destination. Given the focus of our analysis, we abstract from other potential trade distortions. Figure 11 gives an overview of the underlying Armington structure and Equations 26 and 27 present the zero-profit and market clearance conditions for international commodity markets. $y_{r, i}$ is domestic production, $y_{s, i}$ is production by foreign regions and $m_{i, s, m k t}$ are imports of commodity $i$ of market $m k t$ (final demand and sectors) in region $s$. While the Arming- 


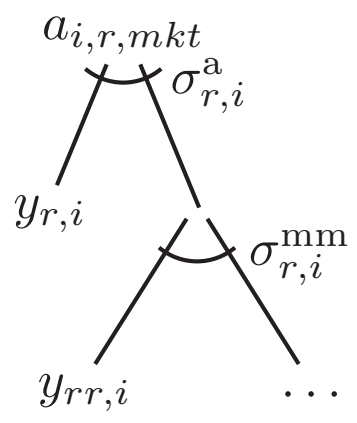

Figure 11: Structure of Armington aggregate.

ton elasticity $\sigma_{r, i}^{a}$ governs the substitutability between domestic and foreign goods, $\sigma_{r, i}^{m m}$ affects the substitution between the same good from different regions.

$$
\begin{gathered}
\pi_{i, r, m k t}^{A} \leq C E S_{i, r, m k t}^{\sigma_{r, i}^{a}}\left[p y_{r, i} ; C E S_{i, r, m k t}^{\sigma_{r, i}^{m m}}\left(p y_{s, i}\right)\right], \text { with } s \neq r \\
m_{i, r, m k t} \geq \sum_{s ; s \neq r}\left(\frac{\partial \pi_{i, r, m k t}^{A}}{\partial p y_{s, i}} A_{i, r, m k t}\right)
\end{gathered}
$$

Each region is represented by one aggregated representative agent who determines final demand. The representative agent maximises his utility by purchasing bundles of consumption goods subject to his budget constraint. Utility of the representative agent $U_{r}$ is given as a Leontief composite of energy $a_{r, e g}$ and a non-energy Armington goods $a_{r, n e g}$. The related zero-profit condition is:

$$
\pi_{(r)}^{U} \leq C E S^{0}\left[C E S^{0}\left(p a_{(n e g, r)}\right), C E S^{0}\left(p a_{(e g, r)}\right)\right]
$$

As described in Equation 29, the budget is determined by factor and tax income. The agent supplies a fix amount of factors. Factors are mobile across sectors within regions but not across regions.

$$
B_{r}=p l_{r} \sum_{i}\left(l_{r, i}\right)
$$

Besides standard economic activity, the model makes provisions for the accounting of $\mathrm{CO}_{2}$. Thereby the model distinguishes between energy related emissions and process 
emissions from sectoral production as well as consumption. From a modelling perspective, when emissions are related to energy, they occur during the production process parallel to the use of energy. Process emission in turn are understood as a byproduct of production and consumption and are thus tied to sectoral output and final demand.

The equilibrium is characterised through three types of equilibrium conditions, market clearance conditions for all commodities and factors, income balances and zero profit conditions. The variables defining the equilibrium are activity levels for the constant-returnsto-scale production, commodity and factor prices, and the price of final consumption. The market clearance condition related to the production of commodities is:

$$
\begin{aligned}
y_{r, i} \geq & \sum_{i i}\left(\frac{\partial \pi_{r, i i}^{y}}{\partial p y_{(r, i)}} y_{r, i i}\right)+\sum_{f d}\left(\frac{\partial \pi_{r}^{U}}{\partial p y_{r, i}} U_{r}\right) \\
& +\sum_{s ; r \neq s} \sum_{m k t}\left(\frac{\partial \pi_{i, s, m k t}^{a}}{\partial p y_{r, i}} a_{i, s, m k t}\right) .
\end{aligned}
$$

The market clearance condition for final demand is:

$$
B_{r} \geq U_{r}
$$

For factor markets the following market clearance conditions must hold:

$$
l_{r, i} \geq \sum_{i i}\left(\frac{\partial \pi_{r, i i}^{Y}}{\partial p l_{r}} Y_{r, i i}\right) .
$$

The model is formulated as a mixed complementarity problem (MCP) in GAMS using the MPSGE syntax Rutherford (1999). The model is solved using the PATH solver (Dirkse and Ferris (1993)).

\section{A.3 Aggregation Scheme}


Table 3: Regional aggregation.

\begin{tabular}{lll}
\hline Short & Region & Associated WIOD Region \\
\hline BRA & Brazil & BRA \\
CHN & China & CHN \\
EAS & Other East Asia & JPN, KOR, TWN \\
EU & European Union (EU27) & AUT, BEL, BGR, CYP, CZE, DEU, DNK, ESP, EST, \\
& & FIN, FRA, GBR, GRC, HUN, IRL, ITA, LTU, LUX, \\
& & LVA, MLT, NLD, POL, PRT, ROM, SVK, SVN, SWE \\
IND & India & IND \\
RUS & Russia & RUS \\
USA & United States of America & USA \\
ROW & Rest of the World & AUS, CAN, IDN, MEX, ROW, TUR \\
\hline
\end{tabular}

Table 4: Sectoral aggregation.

\begin{tabular}{lll}
\hline Short & Sectors & Associated WIOD Sectors \\
\hline FOOD & Food, Beverages, Tobacco & $15 \mathrm{t} 16$ \\
TEXT & Textiles, Leather, Footwear & $17 \mathrm{t} 18,19$ \\
WOOD & Wood Products & 20 \\
PAPE & Pulp, Paper, Printing, Publication & $21 \mathrm{t} 22$ \\
COPN & Coke, Petroleum, Nuclear Fuel & 23 \\
CHEM & Chemicals, Rubber, Plastic & 24,25 \\
ONME & Other Non-metallic mineral & 26 \\
META & Basic Metals, Fabric. Met. & $27 \mathrm{t} 28$ \\
MACH & Machinery Nec. & 29 \\
ELEQ & Electrical \& Optical Equi. & $30 \mathrm{t} 33$ \\
TREQ & Transport Equipment & $34 \mathrm{t} 35$ \\
MANU & Manufacturing Nec., Recycling & $36 \mathrm{t} 37$ \\
TRAN & Transport Activities & $60,61,62,63$ \\
AGRI & Agriculture, Forestry, Fishing & AtB \\
MINI & Mining and Quarrying & $\mathrm{C}$ \\
ELGW & Electricity, Gas, Water & $\mathrm{E}$ \\
CONS & Construction & $\mathrm{F}$ \\
SERV & Sale, Tourism, Financial Services, Health & $50,51,52, \mathrm{H}, 64, \mathrm{~J}, 70,71 \mathrm{t} 74, \mathrm{~L}, \mathrm{M}, \mathrm{N}, \mathrm{O}, \mathrm{P}$ \\
\hline & &
\end{tabular}

